\title{
Análise conjunta de ensaios de cultivares de milho por classes de interação genótipo $x$ ambiente
}

\author{
Lindolfo Storck ${ }^{(1)}$, Alberto Cargnelutti Filho ${ }^{(2)}$ e José Paulo Guadagnin ${ }^{(3)}$
}

\begin{abstract}
(1)Universidade Tecnológica Federal do Paraná, Rodovia PR 469, Km 01, CEP 85501-970 Pato Branco, PR, Brasil. E-mail: lindolfostorck@gmail.com (2)Universidade Federal de Santa Maria, Departamento de Fitotecnia, Avenida Roraima, no 1.000, Camobi, CEP 97105-900 Santa Maria, RS, Brasil. E-mail: alberto.cargnelutti.filho@gmail.com ${ }^{(3)}$ Fundação Estadual de Pesquisa Agropecuária, Rua Gonçalves Dias, o 570, Menino Deus, CEP 90130-060 Porto Alegre, RS, Brasil. E-mail: jpguadagnin@ibest.com.br
\end{abstract}

Resumo - O objetivo deste trabalho foi avaliar a contribuição do uso de classes de cultivares com e sem interação genótipo $\mathrm{x}$ ambiente, na qualidade da análise conjunta de ensaios de milho, quanto à produtividade de grãos. Foram usados dados de produtividade de grãos de milho de 99 ensaios, distribuídos em 12 grupos, cada um com as mesmas cultivares, em diferentes ambientes. Em cada grupo, 9 a 40 cultivares foram avaliadas em 5 a 12 ambientes, durante três anos agrícolas. Para cada grupo, foi realizada análise de variância conjunta e cada cultivar foi testada quanto a sua contribuição para a interação, tendo-se formado duas classes de cultivares: CI, que contribuem para a interação com o ambiente; e SI, que não contribuem para a interação com o ambiente. Para cada classe, realizou-se nova análise de variância conjunta e testou-se a contribuição da cultivar para a interação. A classificação das cultivares quanto a sua contribuição para a interação genótipo x ambiente permite realizar análise conjunta para cada classe de cultivares, com melhor acurácia na comparação das médias das cultivares da classe SI e na análise da interação das cultivares da classe CI.

Termos para indexação: Zea mays, acurácia seletiva, análise de adaptabilidade, indicação de cultivares.

\section{Joint analysis of corn cultivar trials by classes of genotype $x$ environment interaction}

\begin{abstract}
The objective of this work was to evaluate the contribution of the use of classes of cultivars with and without interaction with the environment, on the quality of joint analysis of corn trials for grain productivity. Corn grain productivity data from 99 trials, distributed in 12 groups, each with the same cultivars in different environments, were used. In each group, 9 to 40 cultivars were assessed in 5 to 12 environments during three farming years. For each group, joint analysis of variance was performed and each cultivar was tested for its contribution to the interaction, forming two classes of cultivars: CI, which contribute to the interaction; and SI, which do not contribute to the interaction. For each class, a new joint analysis of variance was performed and the contribution of the cultivar to the interaction was tested. The classification of cultivars based on their contribution to the genotype $\mathrm{x}$ environment interaction allows performing joint analysis for each cultivar class with better accuracy when comparing means of the SI cultivars and when analyzing the interaction of the CI cultivars.
\end{abstract}

Index terms: Zea mays, selective accuracy, adaptability analysis, cultivar recommendation.

\section{Introdução}

O milho (Zea mays L.) é uma cultura importante como fonte de alimento humano e animal. Indicações adequadas de cultivares de milho adaptadas e estáveis consistem numa das principais dificuldades na definição dos pacotes tecnológicos. Para fins de avaliação da produtividade de grãos, as cultivares, na maioria híbridos (simples, triplos e duplos), são classificadas, quanto ao ciclo, em precoce e superprecoce, com vistas a um melhor manejo.
A inconsistência do desempenho das cultivares em resposta aos estímulos ambientais (interação genótipo $\mathrm{x}$ ambiente) dificulta a identificação de cultivares adaptadas e estáveis. Estudos sobre adaptabilidade e estabilidade em grupos de ensaios de milho (Aguiar et al., 2003; Cargnelutti Filho et al., 2009; Santos et al., 2011; Cardoso et al., 2012; Mendes et al., 2012) têm mostrado que a produtividade de grãos de milho é sensível às variações ambientais.

Quando a interação genótipo $\mathrm{x}$ ambiente não é significativa, normalmente realiza-se a comparação de 
médias de cultivares, independentemente de ambiente. No entanto, quando a interação genótipo x ambiente é significativa, é adequado utilizar algum método de análise de adaptabilidade e estabilidade (Vencovsky \& Barriga, 1992; Cruz, 2006; Yan et al., 2007) para descrever o perfil de resposta de cada cultivar frente à variação ambiental.

$\mathrm{Na}$ maioria das análises conjuntas de ensaios de milho (Aguiar et al., 2003; Cargnelutti Filho et al., 2009; Santos et al., 2011; Cardoso et al., 2012; Mendes et al., 2012), a interação genótipo $\mathrm{x}$ ambiente foi significativa. Supõe-se que algumas das cultivares em avaliação possam ser as responsáveis pela significância da interação. Pelo método de Araújo et al. (2012), é possível identificar as cultivares que contribuem significativamente com a interação genótipo x ambiente. Assim, se houver uma classe de cultivares que não interaja com o ambiente (classe SI) e outra classe de cultivares que interaja com o ambiente (classe CI), essas classes podem ser tratadas, estatisticamente, de forma diferenciada. Para as cultivares da classe SI, pode-se realizar análise conjunta e teste de comparação múltipla de médias para identificar as melhores cultivares para a região de abrangência dos ensaios. Para as cultivares da classe CI, pode-se realizar análise conjunta e adotar um dos métodos de análise de adaptabilidade e estabilidade disponíveis (Cruz, 2006; Yan et al., 2007; Cargnelutti Filho et al., 2009; Miranda et al., 2009). Cabe destacar que, para os ensaios de milho e de outras culturas, ainda não são conhecidas as repercussões nas estimativas dos parâmetros dessas análises estatísticas, realizadas separadamente para as cultivares da classe SI e da classe CI, em relação ao conjunto de cultivares $(\mathrm{SI}+\mathrm{CI})$.

O objetivo deste trabalho foi avaliar a contribuição do uso de classes de cultivares, com e sem interação genótipo x ambiente, na qualidade da análise conjunta de ensaios de milho, quanto à produtividade de grãos.

\section{Material e Métodos}

Foram usados dados de produtividade de grãos de milho $\left(\mathrm{Mg} \mathrm{ha}^{-1}\right)$ de 99 ensaios de competição de cultivares realizados no Estado do Rio Grande do Sul, sob a coordenação da Fundação Estadual de Pesquisa Agropecuária. Foram constituídos 12 grupos de ensaios de cultivares de acordo com o ciclo (precoce e superprecoce), a categoria (estadual e indicada) e o ano agrícola (2002/2003, 2003/2004 e 2004/2005)
(Tabela 1). De um ano para o outro, a relação de cultivares pode ser alterada dentro de cada ciclo, ou seja, cultivares da categoria estadual podem ser descartadas, repetidas ou progredir para a categoria das indicadas. $\mathrm{Na}$ categoria indicadas, elas podem ser avaliadas por dois ou mais anos, conforme as decisões das empresas detentoras. Foram avaliados híbridos simples (45\%), triplos (31\%) e duplos (24\%). Os grupos de ensaios em cada um dos 16 locais e as suas respectivas altitudes estão descritos na Tabela 2.

Os ensaios foram conduzidos em delineamento de blocos ao acaso com três repetições, e as parcelas foram constituídas de duas fileiras com $5,0 \mathrm{~m}$ de comprimento, espaçadas em $0,8 \mathrm{~m}$. Os tratos culturais foram realizados de acordo com as recomendações técnicas para o milho. Na maturação, realizou-se a colheita das espigas e corrigiu-se a produtividade de grãos para $13 \%$ de umidade.

Para cada grupo de ensaios (i cultivares em j ambientes), foi realizada análise de variância conjunta (bloco dentro de ambiente, cultivar, ambiente e interação genótipo $\mathrm{x}$ ambiente), tendo-se considerado como fixo o efeito de cultivar e como aleatório, os efeitos de bloco, de ambiente e de interação genótipo $\mathrm{x}$ ambiente. Dos resultados dessa análise, realizada com o aplicativo Genes (Cruz, 2006), foram registrados a média geral, o quadrado médio do erro $(\mathrm{QMe})$, o valor do teste $F$ para cultivar $\left(\mathrm{F}_{\mathrm{C}}\right)$ e o respectivo valor $\mathrm{p}$ do teste $\left(\mathrm{p}_{\mathrm{C}}\right)$, o valor do teste $\mathrm{F}$ para interação genótipo $\mathrm{x}$ ambiente $\left(\mathrm{F}_{\mathrm{GxA}}\right)$ e o respectivo valor $\mathrm{p}$ do teste $\left(\mathrm{p}_{\mathrm{GxA}}\right)$.

Para cada grupo de ensaios, foi realizada análise de adaptabilidade e estabilidade pelo método de Wricke (1965), com uso do aplicativo Genes, opção biometria (Cruz, 2006), e foram registrados os valores de ecovalência (Wi) da cultivar $\mathrm{i}=1,2, \ldots$, I. A estimativa $\mathrm{W}_{\mathrm{i}}$ corresponde à soma de quadrados do efeito da variação ambiental das estimativas dos efeitos da interação genótipo $\mathrm{x}$ ambiente, referente à cultivar $\mathrm{i}$ :

$$
\mathrm{W}_{\mathrm{i}}=\mathrm{K} \sum_{\mathrm{j}=1}^{\mathrm{J}} \hat{\tau}_{\mathrm{ij}}^{2},
$$

em que $\hat{\tau}_{\mathrm{ij}}$ é a estimativa do efeito da interação genótipo $\mathrm{x}$ ambiente obtida em $\mathrm{K}$ repetições (blocos). Ou seja, $\hat{\tau}_{\mathrm{ij}}=\overline{\mathrm{Y}}_{\mathrm{ij} .}-\overline{\mathrm{Y}}_{\mathrm{i} . .}-\overline{\mathrm{Y}}_{\mathrm{j} .}+\overline{\mathrm{Y}}_{\ldots, \ldots}$, em que $\bar{Y}_{\mathrm{ij} .}$ é a estimativa da média da cultivar i no ambiente $\mathrm{j} ; \overline{\mathrm{Y}}_{\mathrm{i} . .}$ é a estimativa da média da cultivar $\mathrm{i} ; \overline{\mathrm{Y}}_{\mathrm{j} .}$ é a estimativa da média do ambiente $\mathrm{j}$; e $\overline{\mathrm{Y}}$... é a estimativa da média geral. As significâncias de $\mathrm{W}_{\mathrm{i}}\left(\mathrm{H}_{0}: \mathrm{W}_{\mathrm{i}}=0\right)$ foram testadas pelo teste $\mathrm{F}$, a $5 \%$ de probabilidade, 
tendo-se usado o método de Araújo et al. (2012): $\mathrm{FW}_{\mathrm{i}}=\left(\mathrm{W}_{\mathrm{i}} / \mathrm{GLw}\right) / \mathrm{QMe}$ com graus de liberdade do numerador e do denominador, respectivamente, iguais a GLw $=(\mathrm{I}-1)(\mathrm{J}-1) / \mathrm{I}$ e GLe $=\mathrm{J}(\mathrm{I}-1)(\mathrm{K}-1)$; QMe é o quadrado médio do erro da análise de variância conjunta. A partir dos valores de $\mathrm{W}_{\mathrm{i}}$, QMe, GLw e GLe, foram realizados os testes de hipóteses com o auxílio de planilha Excel. Nesse método, foram identificadas as cultivares que não contribuíram significativamente para a interação genótipo $\mathrm{x}$ ambiente (classe sem interação), isto é, as cultivares que atendem a hipótese $\mathrm{H}_{0}: \mathrm{W}_{\mathrm{i}}=0$, a $5 \%$ de probabilidade. Assim, com esse critério, obtiveram-se duas classes de cultivares: classe SI, sem interação; e classe CI, com interação.

Em cada grupo de ensaios e para cada uma das classes de cultivares, realizou-se análise conjunta, seguindo o mesmo modelo usado para todas as cultivares, com uso do aplicativo Genes (Cruz, 2006). Dos resultados dessas análises, anotaram-se as estimativas da média, do quadrado médio do erro, do valor do teste F para

Tabela 1. Número de cultivares (nC) de milho (Zea mays) avaliadas nos anos agrícolas de 2002/2003, 2003/2004 e 2004/2005, e número de ensaios (nA), em diferentes grupos de ensaios.

\begin{tabular}{|c|c|c|c|c|c|c|c|c|}
\hline \multirow[t]{2}{*}{$\overline{\text { Grupo }}$} & \multicolumn{3}{|c|}{ Grupo de ensaio } & \multirow[t]{2}{*}{$\mathrm{nC}$} & \multicolumn{3}{|c|}{ Classe genética $^{(2)}$} & \multirow[t]{2}{*}{$\mathrm{nA}$} \\
\hline & Categoria $^{(1)}$ & Ciclo & Ano agrícola & & $\mathrm{HS}$ & HT & $\mathrm{HD}$ & \\
\hline 1 & Estadual & Precoce & $2002 / 2003$ & 36 & 13 & 11 & 12 & 10 \\
\hline 2 & Estadual & Precoce & 2003/2004 & 40 & 17 & 12 & 11 & 11 \\
\hline 3 & Estadual & Precoce & $2004 / 2005$ & 32 & 13 & 12 & 7 & 10 \\
\hline 4 & Estadual & Superprecoce & $2002 / 2003$ & 11 & 6 & 3 & 2 & 9 \\
\hline 5 & Estadual & Superprecoce & 2003/2004 & 9 & 6 & 3 & 0 & 12 \\
\hline 6 & Estadual & Superprecoce & $2004 / 2005$ & 17 & 10 & 5 & 2 & 11 \\
\hline 7 & Indicada & Precoce & $2002 / 2003$ & 27 & 12 & 8 & 7 & 6 \\
\hline 8 & Indicada & Precoce & 2003/2004 & 26 & 11 & 9 & 6 & 7 \\
\hline 9 & Indicada & Precoce & $2004 / 2005$ & 30 & 16 & 6 & 8 & 5 \\
\hline 10 & Indicada & Superprecoce & $2002 / 2003$ & 18 & 7 & 6 & 5 & 5 \\
\hline 11 & Indicada & Superprecoce & $2003 / 2004$ & 16 & 7 & 6 & 3 & 7 \\
\hline 12 & Indicada & Superprecoce & $2004 / 2005$ & 12 & 5 & 4 & 3 & 6 \\
\hline Total & & & & 274 & 123 & 85 & 66 & 99 \\
\hline Classe (\%) & & & & & 45 & 31 & 24 & \\
\hline
\end{tabular}

(1) $\mathrm{Na}$ categoria dos ensaios de cultivares estaduais, foram avaliadas as cultivares ainda não indicadas aos produtores, e, na categoria dos ensaios de cultivares indicadas, foram avaliadas as já indicadas. ${ }^{(2)} \mathrm{HS}$, híbrido simples; HT, híbrido triplo; HD, híbrido duplo.

Tabela 2. Relação dos ambientes - Município, latitude, longitude e altitude - e respectiva participação nos grupos de ensaios de milho.

\begin{tabular}{|c|c|c|c|c|c|}
\hline Ambiente & Município & Latitude & Longitude & Altitude $(\mathrm{m})$ & Participação nos grupos ${ }^{(1)}$ \\
\hline 1 & Aratiba & $27^{\circ} 24^{\prime} \mathrm{S}$ & $52^{\circ} 18^{\prime} \mathrm{O}$ & 458 & $1,2,3,4,5$ e 6 \\
\hline 2 & Capão do Leão & $31^{\circ} 46^{\prime} \mathrm{S}$ & $52^{\circ} 27^{\prime} \mathrm{O}$ & 17 & 3 e 6 \\
\hline 3 & Carazinho & $28^{\circ} 18^{\prime} \mathrm{S}$ & $52^{\circ} 44^{\prime} \mathrm{O}$ & 550 & 3 e 6 \\
\hline 4 & Cruz Alta & $28^{\circ} 36^{\prime} \mathrm{S}$ & $53^{\circ} 41^{\prime} \mathrm{O}$ & 430 & $1,2,3,4,5,6,7,8,9,10,11$ e 12 \\
\hline 5 & Erechim & $27^{\circ} 36^{\prime} \mathrm{S}$ & $52^{\circ} 17^{\prime} \mathrm{O}$ & 760 & $1,2,3,4,5$ e 6 \\
\hline 6 & Não-Me-Toque & $28^{\circ} 25^{\prime} \mathrm{S}$ & $52^{\circ} 48^{\prime} \mathrm{O}$ & 530 & $1,2,3,4,5,6,7,8,9,10,11$ e 12 \\
\hline 7 & Nicolau Vergueiro & $28^{\circ} 32^{\prime} \mathrm{S}$ & $52^{\circ} 28^{\prime} \mathrm{O}$ & 492 & $2,3,5$ e 6 \\
\hline 8 & Palmeiras das Missões & $27^{\circ} 55^{\prime} \mathrm{S}$ & $53^{\circ} 19^{\prime} \mathrm{O}$ & 627 & 2,5 e 6 \\
\hline 9 & Passo Fundo & $28^{\circ} 14^{\prime} \mathrm{S}$ & $52^{\circ} 24^{\prime} \mathrm{O}$ & 687 & $1,3,5,6,7,8,9,11$ e 12 \\
\hline 10 & Pelotas & $31^{\circ} 41^{\prime} \mathrm{S}$ & $52^{\circ} 26^{\prime} \mathrm{O}$ & 177 & $1,2,4,8,11$ e 12 \\
\hline 11 & Rio Pardo & $29^{\circ} 57^{\prime} \mathrm{S}$ & $52^{\circ} 21^{\prime} \mathrm{O}$ & 111 & $1,3,4,5,6,7,8,9,10,11$ e 12 \\
\hline 12 & Roca Sales & $29^{\circ} 17^{\prime} \mathrm{S}$ & $51^{\circ} 53^{\prime} \mathrm{O}$ & 80 & $1,2,4$ e 5 \\
\hline 13 & Santa Maria & $29^{\circ} 43^{\prime} \mathrm{S}$ & $53^{\circ} 43^{\prime} \mathrm{O}$ & 102 & $7,8,9,10,11$ e 12 \\
\hline 14 & São Borja & $28^{\circ} 42^{\prime} \mathrm{S}$ & $55^{\circ} 58^{\prime} \mathrm{O}$ & 70 & $1,2,4$ e 5 \\
\hline 15 & Vacaria & $28^{\circ} 29^{\prime} \mathrm{S}$ & $50^{\circ} 57^{\prime} \mathrm{O}$ & 955 & $2,3,5$ e 6 \\
\hline 16 & Veranópolis & $28^{\circ} 55^{\prime} \mathrm{S}$ & $51^{\circ} 33^{\prime} \mathrm{O}$ & 705 & $1,2,4,5,7,8,10$ e 11 \\
\hline
\end{tabular}

${ }^{(1)}$ Grupos definidos na Tabela 1. 
efeito de cultivar $\left(\mathrm{F}_{\mathrm{C}}\right)$ e do respectivo valor $\mathrm{p}$ do teste $\left(\mathrm{p}_{\mathrm{C}}\right)$, do valor do teste $\mathrm{F}$ para interação genótipo $\mathrm{x}$ ambiente $\left(\mathrm{F}_{\mathrm{GXA}}\right)$ e do respectivo valor $\mathrm{p}$ do teste $\left(\mathrm{p}_{\mathrm{GXA}}\right)$. Também foi estimada a acurácia seletiva (AS), segundo Resende \& Duarte (2007) e Cargnelutti Filho \& Storck (2009), como: AS $=(1-1 / F)^{1 / 2}$, para os efeitos de cultivar e interação genótipo $\mathrm{x}$ ambiente.

A análise de adaptabilidade e estabilidade por meio do modelo AMMI1 (efeito aditivo para cultivar e ambiente e efeito multiplicativo para a interação genótipo x ambiente), com uso do aplicativo GGE biplot (Yan \& Kang, 2002; Yan et al., 2007), foi realizada para cada grupo de ensaios, com todas as cultivares, e também somente com as cultivares da classe CI. Dessas análises, foi anotada a percentagem de explicação (contribuição) captada pelos efeitos principais de ambientes (locais) e de cultivares e do primeiro componente principal da interação genótipo $\mathrm{x}$ ambiente (Zobel et al., 1988). As médias de cada classe foram comparadas pelo teste t "bootstrap" $(\mathrm{p}=0,05$; 5.000 reamostras), com o aplicativo BioEstat (Ayres et al., 2007), supondo que as estatísticas produtividade, $\mathrm{QMe}, \mathrm{F}_{\mathrm{GxA}}, \mathrm{F}_{\mathrm{C}}, \mathrm{p}_{\mathrm{GxA}}$ e $\mathrm{p}_{\mathrm{C}}$ não se ajustam à distribuição normal.

Os resultados para os 12 grupos, das classes $\mathrm{SI}+\mathrm{CI}$, SI e CI, foram registrados em planilha Excel para as determinações das frequências e das médias das estatísticas, por categoria de ensaio e média geral. Das diferenças entre as classes ( $\mathrm{SI}+\mathrm{CI}$, SI e CI), são elaboradas as inferências sobre a eficiência dos métodos de análises.

Os coeficientes de correlação de Pearson foram estimados entre as percentagens de explicação relacionadas ao ambiente, à cultivar e à interação genótipo $\mathrm{x}$ ambiente obtidas para todas as cultivares (classe $\mathrm{SI}+\mathrm{CI}$ ), com os valores encontrados para as cultivares da classe $\mathrm{CI}$.

\section{Resultados e Discussão}

Obteve-se interação genótipo $\mathrm{x}$ ambiente significativa em 11 dos 12 grupos de ensaios (Tabela 3). O grupo 10 (cultivares indicadas superprecoces, 2003) com interação não significativa apresentou média de produtividade de grãos acima da média geral dos grupos; porém, a variância residual (QMe) foi 2,5 vezes acima da média e possivelmente foi a causa da interação não significativa. Os ambientes em que os ensaios de cada grupo foram executados são variáveis quanto à altitude e representam boa parte das áreas de produção de milho no Rio Grande do Sul (Tabela 2). Além disso, a variação na proporção de classes genéticas das cultivares (híbrido simples, duplo e triplo) (Tabela 1) é determinante de elevada interação genótipo x ambiente. Em casos semelhantes, quando há interação genótipo x ambiente, é indicada a caracterização das cultivares por meio de análise de adaptabilidade e estabilidade (Vencovsky \& Barriga, 1992; Yan \& Kang, 2002; Cruz, 2006; Yan et al., 2007; Araújo et al., 2012).

A média da magnitude da interação genótipo $\mathrm{x}$ ambiente (valor de $\mathrm{F}_{\mathrm{GxA}}$ ) foi semelhante para as quatro categorias de ensaios (Tabela 3). Os valores do teste F para cultivar foram superiores aos da interação e não houve correlação entre eles. Os valores do teste F para cultivar nos ensaios da categoria estaduais foram, praticamente, o dobro dos valores nos ensaios da categoria indicadas. Isso mostra que a seleção das cultivares mais produtivas, entre as cultivares estaduais, reduz a variabilidade entre as cultivares da categoria indicadas e também aumenta a média de produtividade. Assim, a escolha das cultivares da categoria estaduais e a sua inclusão na categoria indicadas tem sido realizada de maneira eficiente.

O coeficiente de correlação de Pearson entre as médias de produtividade de grãos e o valor do teste $\mathrm{F}$ para interação $\left(\mathrm{F}_{\mathrm{G} \times \mathrm{A}}\right)$ foi significativo $(\mathrm{r}=-0,55 ; \mathrm{p}<0,05 ; \mathrm{n}=12)$, ou seja, quanto menor a produtividade de grãos, maior é a interação genótipo $\mathrm{x}$ ambiente $\left(\mathrm{F}_{\mathrm{GxA}}\right)$. Os resultados são indicativos de que, em ambientes de produtividades baixas, as cultivares interagem mais fortemente com $o$ ambiente; o contrário ocorre em ambientes de altas produtividades. A magnitude de $\mathrm{F}_{\mathrm{GxA}}$ é determinante da acurácia seletiva, medida de precisão experimental (Resende \& Duarte, 2007) mais adequada (Cargnelutti Filho \& Storck, 2009), neste caso, da precisão da interação. $\mathrm{O}$ erro experimental (QMe) também é correlacionado significativamente com a produtividade $(\mathrm{r}=0,51 ; \mathrm{p}<0,05)$ e com o $\mathrm{F}_{\mathrm{GxA}}(\mathrm{r}=-0,74 ; \mathrm{p}<0,05)$. Diante disso, é possível inferir que, em condições de maior variância do erro, a interação é menor (porque o QMe é o denominador do valor $\mathrm{F}_{\mathrm{GxA}}$ ) e a produtividade é maior.

É importante identificar as cultivares que são responsáveis pela interação (classe $\mathrm{CI}$ ) e as que não causam interação (classe SI). Nesse sentido, em média, 
$52,6 \%$ das cultivares por ensaio foram identificadas como não determinantes da interação, resultado que apresentou variações entre 11,8 e $88,9 \%$. Nos ensaios da categoria de cultivares indicadas precoces (IP) e superprecoces (ISP), houve superioridade da percentagem de cultivares que não interagem (classe SI), o que provavelmente é consequência do critério de seleção das cultivares na categoria estaduais, para inclusão na categoria indicadas.

Quando se realizou a análise conjunta, separadamente, com as cultivares da classe SI e CI, nos mesmos ambientes, observaram-se diferenças significativas, o que não era esperado em relação à classe SI (Tabela 4). Nessa análise, a média do valor $\mathrm{F}_{\mathrm{GXA}}$ interação genótipo $\mathrm{x}$ ambiente foi de 1,365 e a média do valor p foi de $17,01 \%$. No entanto, em 5 dos 12 grupos (41,7\%), a interação foi significativa, o que pode ser justificado pela menor média da variância residual (QMe), que corresponde a $87,5 \%$ da média do QMe da análise conjunta com as cultivares da classe CI. No caso do grupo 10 (categoria de cultivares indicadas superprecoces, 2003), da classe SI+CI, a conclusão foi de que não há interação ( $\mathrm{p}=0,0989)$; entretanto, duas das 18 cultivares foram identificadas como sendo da classe CI. Essas duas cultivares causaram interação significativa quando da análise conjunta das cultivares da classe CI. Essa discordância, que pode ser considerada normal porque é resultado de um novo conjunto de dados, também pode ser contornada com base em estudo de Perecin \& Cargnelutti Filho (2008). Estes autores sugerem o uso de nível de significância menos rigoroso para interpretação do efeito da interação por experimento, em relação às demais fontes de variação da análise de variância. Recomendam, também, o uso de $\mathrm{p}=0,25$ para a interpretação do efeito da interação por experimento e a manutenção do usual $\mathrm{p}=0,05$ para efeitos por comparações. O efeito por comparação é equivalente ao teste de hipótese da contribuição de cada cultivar para com a interação genótipo x ambiente, isto é, a identificação das cultivares das classes SI e CI.

A análise conjunta das cultivares da classe CI resultou em interação significativa em todos os grupos (Tabela 4). A média dos valores de $\mathrm{F}_{\mathrm{GxA}}$ foi igual a 4,090 e foi significativamente superior (teste t "bootstrap" com 5.000 reamostras) à das cultivares da classe SI e superior à média de $\mathrm{F}_{\mathrm{GxA}}$ quando todas as cultivares foram usadas na análise conjunta (média igual a 2,460). Dessa forma, ao se retirar as cultivares da classe SI, a magnitude da interação (valor de $\mathrm{F}_{\mathrm{GxA}}$ ) foi $66 \%$ superior, o que pode melhorar as estimativas dos parâmetros da análise de estabilidade e adaptabilidade.

Tabela 3. Número de cultivares (nC) de milho (Zea mays), média da produtividade de grãos ( $\left.\mathrm{Mg}^{-1}\right)$, quadrado médio do erro da análise de variância conjunta $(\mathrm{QMe})$, valor do teste $\mathrm{F}$ para cultivar $\left(\mathrm{F}_{\mathrm{C}}\right)$ e para interação genótipo $\mathrm{x}$ ambiente $\left(\mathrm{F}_{\mathrm{GxA}}\right)$ e respectivas significâncias $\left(\mathrm{p}_{\mathrm{C}}\right.$ e $\left.\mathrm{p}_{\mathrm{GxA}}\right)$, número $(\mathrm{nSI})$ e percentagem $(\mathrm{SI} \%)$ de cultivares que não interagem com o ambiente.

\begin{tabular}{|c|c|c|c|c|c|c|c|c|c|}
\hline Grupo $^{(1)}$ & $\mathrm{nC}$ & Produtividade & QMe & $\mathrm{F}_{\mathrm{C}}$ & $\mathrm{F}_{\mathrm{GxA}}$ & $\mathrm{p}_{\mathrm{C}}$ & $\mathrm{p}_{\mathrm{GxA}}$ & $\mathrm{nSI}$ & SI (\%) \\
\hline 1 & 36 & 7.405 & 0,8436 & 13,670 & 2,954 & 0,00 & 0,00 & 17 & 47,2 \\
\hline 2 & 40 & 7.940 & 0,9293 & 9,794 & 1,796 & 0,00 & 0,00 & 21 & 52,5 \\
\hline 3 & 32 & 4.458 & 0,5908 & 6,820 & 2,947 & 0,00 & 0,00 & 11 & 34,4 \\
\hline 4 & 11 & 7.268 & 0,8863 & 16,341 & 2,192 & 0,00 & 0,00 & 6 & 54,5 \\
\hline 5 & 9 & 8.104 & 0,8632 & 12,838 & 1,633 & 0,00 & 0,01 & 6 & 66,7 \\
\hline 6 & 17 & 4.676 & 0,4178 & 8,695 & 3,550 & 0,00 & 0,00 & 2 & 11,8 \\
\hline 7 & 27 & 7.801 & 1,0743 & 5,300 & 2,468 & 0,00 & 0,00 & 19 & 70,4 \\
\hline 8 & 26 & 7.958 & 0,7235 & 7,769 & 2,625 & 0,00 & 0,00 & 12 & 46,2 \\
\hline 9 & 30 & 5.615 & 0,7458 & 3,689 & 2,363 & 0,00 & 0,00 & 20 & 66,7 \\
\hline 10 & 18 & 7.757 & 2,2173 & 2,796 & 1,286 & 0,00 & 0,10 & 16 & 88,9 \\
\hline 11 & 16 & 8.404 & 0,8031 & 10,213 & 2,929 & 0,00 & 0,00 & 8 & 50,0 \\
\hline 12 & 12 & 4.957 & 0,4364 & 9,639 & 2,782 & 0,00 & 0,00 & 5 & 41,7 \\
\hline Média EP & 36,0 & 6.601 & 0,7879 & 10,095 & 2,565 & 0,00 & 0,00 & - & 44,7 \\
\hline Média ESP & 12,3 & 6.682 & 0,7224 & 12,625 & 2,458 & 0,00 & 0,01 & - & 44,3 \\
\hline Média IP & 27,7 & 7.124 & 0,8479 & 5,586 & 2,485 & 0,00 & 0,00 & - & 61,1 \\
\hline Média ISP & 15,3 & 7.039 & 1,1523 & 7,549 & 2,332 & 0,00 & 0,03 & - & 60,2 \\
\hline Média geral & 22,8 & 6.862 & 0,8776 & 8,964 & 2,460 & 0,00 & 0,01 & - & 52,6 \\
\hline
\end{tabular}

${ }^{(1)}$ Ensaios estaduais (E) de cultivares precoces (P) e superprecoces (SP); ensaios de cultivares indicadas precoces (IP) e de cultivares indicadas superprecoces (ISP). 
A média do valor do teste $\mathrm{F}$ para cultivar $\left(\mathrm{F}_{\mathrm{C}}\right)$ foi menor para as cultivares da classe CI $(7,853)$ quando comparada à das cultivares da classe SI $(9,912)$ ou a de todas as demais cultivares $(8,964)$. Isso pode ser compreendido pela interação complexa entre algumas cultivares, o que atenua as diferenças entre as médias destas e o valor do teste $\mathrm{F}$ para cultivar.
O coeficiente de correlação de Pearson entre a média geral da produtividade de grãos, obtida com uso das cultivares da classe SI, e a média geral de produtividade, obtida com uso das cultivares da classe CI, foi positivo e significativo $(r=0,93 ; \mathrm{p}<0,01)$. Esse fato foi observado tanto para as cultivares da classe SI quanto para as da classe CI, quando um grupo de

Tabela 4. Número de cultivares $(\mathrm{nC})$ de milho (Zea mays), média da produtividade de grãos $\left(\mathrm{Mg}_{\mathrm{g}} \mathrm{a}^{-1}\right)$, quadrado médio do erro da análise de variância conjunta $(\mathrm{QMe})$, valor do teste $\mathrm{F}$ para interação genótipo $\mathrm{x}$ ambiente $\left(\mathrm{F}_{\mathrm{GxA}}\right)$ e para efeito de cultivar $\left(\mathrm{F}_{\mathrm{C}}\right)$ e respectivas significâncias $\left(\mathrm{p}_{\mathrm{G} \times \mathrm{A}} \mathrm{e} \mathrm{p}_{\mathrm{C}}\right.$ ), para análise da classe de cultivares que não interagem com o ambiente (SI) e da classe de cultivares que interagem com o ambiente (CI).

\begin{tabular}{|c|c|c|c|c|c|c|c|c|}
\hline Grupo & Categoria $^{(2)}$ & $\mathrm{nC}$ & Produtividade & QMe & $\mathrm{F}_{\mathrm{GxA}}$ & $\mathrm{F}_{\mathrm{C}}$ & $\mathrm{p}_{\mathrm{GxA}}$ & $\mathrm{p}_{\mathrm{C}}$ \\
\hline & & \multicolumn{7}{|c|}{ Classe SI } \\
\hline 1 & EP & 17 & 7.525 & 0,7063 & 1,537 & 18,450 & 0,00 & 0,00 \\
\hline 2 & EP & 21 & 7.872 & 0,8493 & 1,321 & 7,212 & 0,01 & 0,00 \\
\hline 3 & EP & 11 & 4.293 & 0,5676 & 1,225 & 19,404 & 0,12 & 0,00 \\
\hline 4 & $\mathrm{ESP}$ & 6 & 7.074 & 0,7471 & 1,547 & 13,355 & 0,05 & 0,00 \\
\hline 5 & ESP & 6 & 7.807 & 0,9225 & 0,909 & 9,037 & 0,65 & 0,00 \\
\hline 6 & ESP & 2 & 4.656 & 0,3587 & 1,709 & 3,425 & 0,14 & 0,08 \\
\hline 7 & IP & 19 & 7.710 & 1,2126 & 1,160 & 11,395 & 0,19 & 0,00 \\
\hline 8 & IP & 12 & 8.067 & 0,7027 & 1,236 & 9,011 & 0,15 & 0,00 \\
\hline 9 & IP & 20 & 5.638 & 0,7754 & 1,440 & 5,770 & 0,02 & 0,00 \\
\hline 10 & ISP & 16 & 7.881 & 2,0247 & 1,023 & 3,077 & 0,45 & 0,00 \\
\hline 11 & ISP & 8 & 8.808 & 0,8431 & 1,184 & 6,736 & 0,25 & 0,00 \\
\hline 12 & ISP & 5 & 4.661 & 0,3668 & 2,087 & 12,075 & 0,02 & 0,00 \\
\hline Média EP & & & 6.563 & 0,7077 & 1,361 & 15,022 & 0,04 & 0,00 \\
\hline Média ESP & & & 6.512 & 0,6761 & 1,388 & 8,606 & 0,28 & 0,03 \\
\hline Média IP & & & 7.139 & 0,8969 & 1,279 & 8,725 & 0,12 & 0,00 \\
\hline Média ISP & & & 7.116 & 1,0782 & 1,431 & 7,296 & 0,24 & 0,00 \\
\hline \multirow[t]{2}{*}{ Média geral $^{(1)}$} & & & $6.833 \mathrm{a}$ & $0,8397 \mathrm{a}$ & $1,365 \mathrm{~b}$ & $9,912 \mathrm{a}$ & $0,17 \mathrm{a}$ & $0,01 \mathrm{a}$ \\
\hline & & \multicolumn{7}{|c|}{ Classe CI } \\
\hline 1 & EP & 19 & 7.298 & 0,9606 & 4,023 & 12,334 & 0,00 & 0,00 \\
\hline 2 & EP & 19 & 8.016 & 1,0363 & 2,185 & 11,498 & 0,00 & 0,00 \\
\hline 3 & EP & 21 & 4.545 & 0,5866 & 3,921 & 4,770 & 0,00 & 0,00 \\
\hline 4 & ESP & 5 & 7.499 & 1,0097 & 3,257 & 17,257 & 0,00 & 0,00 \\
\hline 5 & ESP & 3 & 8.698 & 0,6558 & 3,914 & 9,695 & 0,00 & 0,00 \\
\hline 6 & ESP & 15 & 4.679 & 0,4087 & 3,981 & 8,966 & 0,00 & 0,00 \\
\hline 7 & IP & 8 & 8.017 & 0,7357 & 8,114 & 1,610 & 0,00 & 0,14 \\
\hline 8 & IP & 14 & 7.865 & 0,7445 & 3,794 & 7,549 & 0,00 & 0,00 \\
\hline 9 & IP & 10 & 5.567 & 0,7434 & 4,254 & 2,307 & 0,00 & 0,02 \\
\hline 10 & ISP & 2 & 6.768 & 3,3101 & 3,748 & 0,556 & 0,04 & 0,47 \\
\hline 11 & ISP & 8 & 8.001 & 0,8234 & 4,618 & 9,716 & 0,00 & 0,00 \\
\hline 12 & ISP & 7 & 5.170 & 0,4990 & 3,274 & 7,974 & 0,00 & 0,00 \\
\hline Média EP & & & 6.620 & 0,8612 & 3,377 & 9,534 & 0,00 & 0,00 \\
\hline Média ESP & & & 6.959 & 0,6914 & 3,718 & 11,973 & 0,00 & 0,00 \\
\hline Média IP & & & 7.150 & 0,7412 & 5,387 & 3,822 & 0,00 & 0,06 \\
\hline Média ISP & & & 6.646 & 1,5442 & 3,880 & 6,082 & 0,01 & 0,16 \\
\hline Média geral & & & $6.844 a$ & $0,9595 \mathrm{a}$ & $4,090 \mathrm{a}$ & $7,853 \mathrm{a}$ & $0,00 \mathrm{~b}$ & $0,05 \mathrm{a}$ \\
\hline Correlação entre SI e C & - & - & $0,93 * *$ & $0,89 * *$ & $-0,27_{\mathrm{ns}}$ & $0,28^{\mathrm{ns}}$ & - & - \\
\hline
\end{tabular}

${ }^{(1)}$ Médias não seguidas por letras iguais diferem pelo teste t "bootstrap" (5.000 reamostras), a 5\% de probabilidade. (2)Ensaios estaduais de cultivares precoces (P) e superprecoces (SP); ensaios de cultivares indicadas precoces (IP) e de cultivares indicadas superprecoces (ISP). ns Não significativo. **Correlação significativa a $1 \%$ de probabilidade entre as duas classes de cultivares $(\mathrm{n}=12)$. 
ambientes tem maior produtividade. Isso significa que a representatividade da produtividade das duas classes de cultivares tem média semelhante e variabilidades concordantes.

Além disso, cultivares da classe CI, por interagirem com o ambiente, são mais sensíveis à variação ambiental (tem maior adaptabilidade) e podem ter menor média geral de produtividade. Para as cultivares da classe SI, apenas em um dos grupos (grupo 6), não foi constatada significância entre as duas cultivares e a interação não foi significativa.

A variabilidade dos dados de produtividade de grãos (Tabela 5) é explicada principalmente pelo fator ambiental (locais), ao se utilizar todas as cultivares de cada ensaio (média de $68,1 \%$ ) ou apenas as cultivares da classe CI (média de 62,0\%). A média da variabilidade explicada pelas cultivares é menor do que a decorrente do ambiente, e não houve diferença significativa entre

Tabela 5. Categoria do grupo de ensaios de cultivares de milho (Zea mays), número de cultivares (nC), percentagem de explicação da variabilidade pelo modelo AMMI1 para efeitos de ambiente (A), de cultivar (C) e da interação genótipo x ambiente (GxA) na análise da produtividade de grãos, com as cultivares que interagem (CI) e que não interagem (SI) com o ambiente, analisadas conjuntamente, e com as que interagem com o ambiente (CI), analisadas separadamente.

\begin{tabular}{|c|c|c|c|c|c|c|}
\hline Grupo & Categoria $^{(2)}$ & $\mathrm{nC}$ & $\mathrm{A}$ & $\mathrm{C}$ & GxA & Soma \\
\hline & \multicolumn{6}{|c|}{ Classes SI+CI } \\
\hline 1 & EP & 36 & 69,3 & 18,5 & 3,8 & 91,6 \\
\hline 2 & $\mathrm{EP}$ & 40 & 81,8 & 9,0 & 2,3 & 93,1 \\
\hline 3 & $\mathrm{EP}$ & 32 & 41,0 & 25,4 & 10,9 & 77,3 \\
\hline 4 & ESP & 11 & 71,3 & 19,3 & 3,2 & 93,8 \\
\hline 5 & ESP & 9 & 84,7 & 8,3 & 2,9 & 95,9 \\
\hline 6 & ESP & 17 & 39,3 & 28,3 & 10,7 & 78,3 \\
\hline 7 & IP & 27 & 66,9 & 17,0 & 7,7 & 91,6 \\
\hline 8 & IP & 26 & 63,7 & 20,5 & 8,2 & 92,4 \\
\hline 9 & IP & 30 & 77,6 & 10,7 & 5,6 & 93,9 \\
\hline 10 & ISP & 18 & 81,1 & 7,8 & 4,6 & 93,5 \\
\hline 11 & ISP & 16 & 57,9 & 26,5 & 5,9 & 90,3 \\
\hline 12 & ISP & 12 & 82,9 & 11,3 & 2,7 & 96,9 \\
\hline Média EP & - & - & 64,0 & 17,6 & 5,7 & 87,3 \\
\hline Média ESP & - & - & 65,1 & 18,6 & 5,6 & 89,3 \\
\hline Média IP & - & - & 69,4 & 16,1 & 7,2 & 92,6 \\
\hline Média ISP & - & - & 74,0 & 15,2 & 4,4 & 93,6 \\
\hline \multirow[t]{2}{*}{ Média geral $^{(1)}$} & - & - & $68,1 \mathrm{a}$ & $16,9 \mathrm{a}$ & $5,7 \mathrm{~b}$ & $90,7 \mathrm{a}$ \\
\hline & \multicolumn{6}{|c|}{ Classe CI } \\
\hline 1 & EP & 19 & 61,1 & 22,5 & 5,6 & 89,2 \\
\hline 2 & $\mathrm{EP}$ & 19 & 77,2 & 12,2 & 3,0 & 92,4 \\
\hline 3 & $\mathrm{EP}$ & 21 & 40,5 & 20,6 & 13,7 & 74,8 \\
\hline 4 & ESP & 5 & 63,9 & 24,7 & 5,5 & 94,1 \\
\hline 5 & ESP & 3 & 84,4 & 7,3 & 5,1 & 96,8 \\
\hline 6 & ESP & 15 & 37,9 & 29,3 & 11,2 & 78,4 \\
\hline 7 & IP & 8 & 64,4 & 8,7 & 14,7 & 87,8 \\
\hline 8 & IP & 14 & 56,1 & 24,5 & 11,2 & 91,8 \\
\hline 9 & IP & 10 & 69,1 & 11,3 & 12,9 & 93,3 \\
\hline 10 & ISP & 2 & - & - & - & - \\
\hline 11 & ISP & 8 & 45,5 & 33,7 & 9,2 & 88,4 \\
\hline 12 & ISP & 7 & 82,1 & 11,0 & 3,4 & 96,5 \\
\hline Média EP & - & - & 59,6 & 18,4 & 7,4 & 85,5 \\
\hline Média ESP & - & - & 62,1 & 20,4 & 7,3 & 89,8 \\
\hline Média IP & - & - & 63,2 & 14,8 & 12,9 & 91,0 \\
\hline Média ISP & - & - & 63,8 & 22,4 & 6,3 & 92,5 \\
\hline Média geral & - & - & $62,0 \mathrm{a}$ & $18,7 \mathrm{a}$ & $8,7 \mathrm{a}$ & $89,4 \mathrm{a}$ \\
\hline
\end{tabular}

${ }^{(1)}$ Médias não seguidas por letras iguais diferem pelo teste t "bootstrap" (5.000 reamostras), a 5\% de probabilidade. (2)Ensaios estaduais (E) de cultivares precoces (P) e superprecoces (SP); ensaios de cultivares indicadas precoces (IP) e de cultivares indicadas superprecoces (ISP). 
as duas classes $-16,9 \%$ para todas as cultivares e $18,7 \%$ para as cultivares da classe CI.

Vale ressaltar que a média da variabilidade explicada pela interação de efeito multiplicativo foi superior quando apenas as cultivares da classe $\mathrm{CI}$ foram utilizadas. Isso mostra a conveniência em se analisar as classes de cultivares, SI e CI, separadamente. Portanto, é possível inferir que as cultivares da classe SI, quando presentes nessa análise, podem viesar as estimativas dos efeitos da interação.

Entre os 12 grupos de ensaios, a percentagem de explicação causada pelo ambiente variou entre 39,3 e $84,7 \%$ ao se usar todas as cultivares, e valores semelhantes (mínimo de 37,9 e máximo de 84,4\%) foram observados com apenas as cultivares da classe CI. Amplitudes entre grupos, para essas estimativas, também foram elevadas para os efeitos de cultivares e para a interação nas duas classes de cultivares. Entretanto, no total da percentagem de explicação, essa amplitude foi pequena, o que significa que os ambientes usados nos três anos de ensaios tiveram efeitos sobre as cultivares e apresentaram interação bem diversificada e representativa da realidade. Valores altos de percentagem explicada pelo ambiente, para produtividade de grãos, também foram relatados na cultura do trigo (Triticum aestivum) por Silva et al. (2011) e Benin et al. (2012), que demonstraram a maior importância do ambiente em relação à cultivar e à interação, na determinação da produtividade de grãos de trigo.
A média da percentagem de variação explicada pela interação, 5,7\% (classe SI+CI) e 8,7\% (classe CI), é inferior aos $23,2 \%$ estimados para um grupo de ensaios de milho com 55 cultivares em 12 ambientes (Costa et al., 2010) e aos $21,9 \%$, para um grupo de ensaios de milho com 23 cultivares em 11 ambientes (Oliveira et al., 2010). No presente trabalho, o valor máximo obtido, de 14,7\% para o grupo 7 (IP em 2003), com oito cultivares da classe CI em seis ambientes, ainda é mais baixo, possivelmente em razão do menor número de ambientes utilizados. Os métodos AMMI são úteis quando a variação explicada pela interação é maior, o que pode justificar a aplicação desse método apenas nas cultivares da classe CI.

Não houve diferença entre todas as cultivares e as da classe $\mathrm{CI}$ quanto à proporção de variação decorrente do ambiente, da cultivar e do total (cultivar + ambiente + interação), mas observou-se correlação linear positiva e significativa entre as duas situações (classes SI+CI e CI), nas quatro medidas de variabilidade explicada (Tabela 6). Pode-se, então, inferir que a retirada das cultivares que não interagem com o ambiente não invalida as interpretações das análises por classe de cultivar. A principal vantagem ao se analisar as cultivares SI, separadamente, é permitir uma recomendação das cultivares mais produtivas ao sistema de produção, de forma geral, sem considerar a variação ambiental que esse grupo de ensaios representa e também sem prejudicar a análise e a

Tabela 6. Estimativas dos coeficientes de correlação de Pearson para os valores da percentagem de explicação da variabilidade pelo modelo AMMI1, referente aos efeitos de ambiente (A), de cultivar (C), da interação genótipo x ambiente (GxA) e da soma $(\mathrm{A}+\mathrm{C}+\mathrm{GxA})$ na análise da produtividade de grãos de cultivares de milho (Zea mays), com as cultivares que interagem (CI) e que não interagem (SI) com o ambiente, analisadas conjuntamente, e com as cultivares que interagem e que não interagem com o ambiente, analisadas separadamente, com a percentagem do número total de cultivares (nSI\%).

\begin{tabular}{|c|c|c|c|c|c|c|c|c|}
\hline \multirow[t]{2}{*}{ Parâmetro } & \multicolumn{3}{|c|}{ Classes SI+CI } & \multirow[t]{2}{*}{ Soma } & \multicolumn{3}{|c|}{ Classe CI } & \multirow[t]{2}{*}{ Soma } \\
\hline & A & $\mathrm{C}$ & GxA & & A & $\mathrm{C}$ & GxA & \\
\hline \multicolumn{9}{|c|}{ Classes SI+CI } \\
\hline A & - & & & & & & & \\
\hline $\mathrm{C}$ & $-0,929 *$ & - & & & & & & \\
\hline GxA & $-0,893 *$ & $0,732 *$ & - & & & & & \\
\hline Soma & $0,935^{*}$ & $-0,754^{*}$ & $-0,853^{*}$ & - & & & & \\
\hline \multicolumn{9}{|c|}{ Classes CI } \\
\hline A & $0,966^{*}$ & $-0,964^{*}$ & $-0,838 *$ & $0,853^{*}$ & - & & & \\
\hline $\mathrm{C}$ & $-0,681^{*}$ & $0,866^{*}$ & 0,406 & $-0,486$ & $-0,804^{*}$ & - & & \\
\hline GxA & $-0,625^{*}$ & 0,495 & $0,849 *$ & $-0,544$ & $-0,617 *$ & 0,142 & - & \\
\hline Soma & $0,938 *$ & $-0,775^{*}$ & $-0,862^{*}$ & $0,981^{*}$ & $0,862 *$ & $-0,457^{*}$ & $-0,608 *$ & - \\
\hline $\mathrm{nSI} \%$ & $0,712^{*}$ & $-0,718^{*}$ & $-0,491$ & $0,669^{*}$ & $0,639^{*}$ & $-0,605^{*}$ & $-0,037$ & $0,651^{*}$ \\
\hline
\end{tabular}

*Significativo pelo teste $\mathrm{t}$, a $5 \%$ de probabilidade. 
interpretação das demais cultivares (classe CI) com o uso de outros métodos.

É possível que a análise conjunta realizada apenas com as cultivares que interagem com o ambiente (classe CI) tenha algumas estimativas de parâmetros modificadas em função do uso de diferentes métodos ou modelos de análise.

A contribuição de cultivares na explicação da variabilidade dos dados estimada com todas as cultivares está correlacionada positivamente e significativamente $(\mathrm{r}=0,866, \mathrm{p}<0,05)$ com a mesma contribuição estimada com o uso das cultivares da classe CI. Dessa forma, a retirada das cultivares da classe SI da análise não deve prejudicar as inferências obtidas nas análises das demais cultivares. Correlações altas, positivas e significativas também são observadas para os efeitos de ambiente e da interação genótipo x ambiente, para a soma dos efeitos de cultivar, ambiente e interação genótipo $\mathrm{x}$ ambiente $(\mathrm{r}=0,981, \mathrm{p}<0,05)$.

Com relação à análise dos grupos com todas as cultivares, quanto maior a percentagem de cultivares da classe SI - nSI\% (Tabela 6), menor é a percentagem de explicação da variação resultante da interação $(\mathrm{r}=-0,491 ; \mathrm{p}<0,05)$, o que obviamente não ocorre quando são analisadas apenas as cultivares da classe $\mathrm{CI}(\mathrm{r}=-0,038)$.

Estimativas dos valores dos testes $\mathrm{F}\left(\mathrm{F}_{\mathrm{GxA}}\right.$ e $\left.\mathrm{F}_{\mathrm{C}}\right)$ mais elevadas significam maior AS, em que a precisão de um experimento é muito alta quando $\mathrm{AS}>0,90$, equivalente a $F>5,26$. Assim, ao se usar todas as cultivares, a média da AS referente à interação genótipo $x$ ambiente foi igual a 0,74 e não superou o limite de 0,90 em nenhum dos 12 grupos. Contudo, ao se usar apenas as cultivares da classe CI, a média da AS, referente ao efeito da interação, foi igual a 0,86 , e $66 \%$ dos grupos de ensaios foram classificados como de precisão muito alta. Desse modo, a retirada das cultivares da classe SI da análise conjunta melhora a precisão das estimativas do efeito da interação. No caso do efeito de cultivar, a média de AS na classe CI foi igual a 0,820 , e, na classe SI, igual a 0,928 . A superioridade de $10 \%$ na acurácia seletiva, na comparação das cultivares da classe SI, é indicativo de vantagem em se analisar os dados dos ensaios de competição de cultivares de milho por classe de interação.

Finalmente, pode-se propor que as análises dos ensaios da rede de avaliação de cultivares de milho sejam realizadas, separadamente, para as cultivares das classes SI e CI. Portanto, os testes de hipóteses seriam realizados com as variâncias do erro (QMe) específicas de cada classe de cultivares e as conclusões seriam por finalidade. Para as cultivares da classe SI, seria suficiente aplicar um teste de comparação de médias (com maior AS), e as melhores cultivares seriam indicadas para qualquer um dos ambientes onde foram avaliadas. No entanto, para as cultivares da classe CI, a finalidade da análise é identificar as cultivares quanto à adaptabilidade e à estabilidade, e, de maneira usual, selecionar as melhores para uso agrícola em ambientes de características específicas (superior, médio, inferior ou no geral, entre outros). Os resultados dessa análise, sem a presença das cultivares da classe SI, nesse caso desnecessárias, podem mostrar melhor o comportamento de cada cultivar em relação à variação ambiental, porque têm maior acurácia seletiva para o efeito da interação. O não haver prejuízos na interpretação da análise das cultivares da classe CI é motivo suficiente para a realização da análise das cultivares da classe SI separadamente.

\section{Conclusões}

1. A identificação das cultivares, quanto a sua contribuição com a interação genótipo x ambiente, permite realizar análise conjunta para cada classe de cultivares - SI, sem interação; e CI, com interação.

2. A análise conjunta dos ensaios com as cultivares de milho que interagem com o ambiente tem maior acurácia seletiva quanto ao efeito de interação genótipo $\mathrm{x}$ ambiente, sem alterar a acurácia da comparação das médias das cultivares que não interagem, o que possibilita a identificação de cultivares para ambientes mais específicos, sem a interferência das cultivares que não interagem.

3. A análise conjunta de ensaios de milho em duas classes é adequada para melhorar a caracterização das cultivares.

\section{Agradecimentos}

Ao Conselho Nacional de Desenvolvimento Científico e Tecnológico (CNPq), pela concessão de bolsa de produtividade em pesquisa; e à Coordenação de Aperfeiçoamento de Pessoal de Nível Superior (Capes), pela concessão de bolsa de professor visitante nacional sênior (PVNS).

Pesq. agropec. bras., Brasília, v.49, n.3, p.163-172, mar. 2014 DOI: $10.1590 / \mathrm{S} 0100-204 \mathrm{X} 2014000300002$ 


\section{Referências}

AGUIAR, A.M.; CARLINI-GARCIA, L.A.; SILVA, A.R. da; SANTOS, M.F.; GARCIA, A.A.F.; SOUZA JUNIOR, C.L. de. Combining ability of inbred lines of maize and stability of their respective single-crosses. Scientia Agricola, v.60, p.83-89, 2003. DOI: $10.1590 / \mathrm{S} 0103-90162003000100013$.

ARAÚJO, M.F.C.; ARAÚJO, L.B. de; FARIA, P.N.; DIAS, C.T.S. Statistical test for genotype and environment contribution in the genotypes x environments interaction matrix. Interciencia, v.37, p.515-519, 2012.

AYRES, M.; AYRES JUNIOR, M.; AYRES, D.L.; SANTOS, A. de A. dos S. BioEstat - aplicações estatísticas nas áreas das ciências biomédicas. Belém: Sociedade Civil Mamirauá, 2007. 380p.

BENIN, G.; PINNOW, C.; SILVA, C.L. da; PAGLIOSA, E.S.; BECHE, E.; BORNHOFEN, E.; MUNARO, L.B.; SILVA, R.R. Análises biplot na avaliação de cultivares de trigo em diferentes níveis de manejo. Bragantia, v.71, p.28-36, 2012.

CARDOSO, M.J.; CARVALHO, H.W.L. de; ROCHA, L.M.P.; PACHECO, C.A.P.; GUIMARÃES, L.J.M.; GUIMARÃES, P.E. de O.; PARENTONY, S.N.; OLIVEIRA, I.R. de. Identificação de cultivares de milho com base na análise de estabilidade fenotípica no Meio-Norte brasileiro. Revista Ciência Agronômica, v.43, p.346-353, 2012. DOI: 10.1590/S1806-66902012000200018.

CARGNELUTTI FILHO, A.; STORCK, L. Medidas do grau de precisão experimental em ensaios de competição de cultivares de milho. Pesquisa Agropecuária Brasileira, v.44, p.111-117, 2009. DOI: $10.1590 /$ S0100-204X2009000200001.

CARGNELUTTI FILHO, A.; STORCK, L.; RIBOLDI, J.; GUADAGNIN, J.P. Associação entre métodos de adaptabilidade e estabilidade em milho. Ciência Rural, v.39, p.340-347, 2009. DOI: $10.1590 / \mathrm{S} 0103-84782008005000080$.

COSTA, E.F.N.; SOUZA, J.C. de; LIMA, J.L.; CARDOSO, G.A. Interação entre genótipos e ambientes em diferentes tipos de híbridos de milho. Pesquisa Agropecuária Brasileira, v.45, p.1433-1440, 2010. DOI: 10.1590/S0100-204X2010001200014.

CRUZ, C.D. Programa Genes: biometria. Viçosa: Ed. da UFV, 2006. 382p.

EBERHART, S.A.; RUSSELL, W.A. Stability parameters for comparing varieties. Crop Science, v.6, p.36-40, 1966. DOI: 10.2135/cropsci1966.0011183X000600010011x.

MENDES, F.F.; GUIMARÃES, L.J.M.; SOUZA, J.C.; GUIMARÃES, P.E.O.; PACHECO, C.A.P.; MACHADO, J.R.A.; MEIRELLES, W.F.; SILVA, A.R.; PARENTONI, S.N. Adaptability and stability of maize varieties using mixed model methodology.
Crop Breeding and Applied Biotechnology, v.12, p.111-117, 2012. DOI: $10.1590 /$ S1984-70332012000200003.

MIRANDA, G.V.; SOUZA, L.V. de; GUIMARÃES, L.J.M.; NAMORATO, H.; OLIVEIRA, L.R.; SOARES, M.O. Multivariate analyses of genotype $\mathrm{x}$ environment interaction of popcorn. Pesquisa Agropecuária Brasileira, v.44, p.45-50, 2009. DOI: 10.1590/S0100-204X2009000100007.

OLIVEIRA, R.L. de; VON PINHO, R.G.; BALESTRE, M.; FERREIRA, D.V. Evaluation of maize hybrids and environmental stratification by the methods AMMI and GGE biplot. Crop Breeding and Applied Biotechnology, v.10, p.247-253, 2010. DOI: $10.1590 /$ S1984-70332010000300010.

PERECIN, D.; CARGNELUTTI FILHO, A. Efeitos por comparações e por experimento em interações de experimentos fatoriais. Ciência e Agrotecnologia, v.32, p.68-72, 2008. DOI: 10.1590/S1413-70542008000100010.

RESENDE, M.D.V. de; DUARTE, J.B. Precisão e controle de qualidade em experimentos de avaliação de cultivares. Pesquisa Agropecuária Tropical, v.37, p.182-194, 2007.

SANTOS, E.L. dos; GARBUGLIO, D.D.; ARAUJO, P.M. de; GERAGE, A.C.; SHIOGA, P.S.; PRETE, C.E.C. Uni and multivariate methods applied to studies of phenotypic adaptability in maize (Zea mays L.). Acta Scientiarum. Agronomy, v.33, p.633-640, 2011. DOI: 10.4025/actasciagron.v33i4.6953.

SILVA, R.R.; BENIN, G.; SILVA, G.O. da; MARCHIORO, V.S.; ALMEIDA, J.L. de; MATEI, G. Adaptabilidade e estabilidade de cultivares de trigo em diferentes épocas de semeadura, no Paraná. Pesquisa Agropecuária Brasileira, v.46, p.1439-1447, 2011. DOI: $10.1590 /$ S0100-204X2011001100004.

VENCOVSKY, R.; BARRIGA, P. Genética biométrica no fitomelhoramento. Ribeirão Preto: Sociedade Brasileira de Genética, 1992. 486p.

WRICKE, G. Zur Berechning der okovalenz bei sommerweizen und hafer. Zeitschrift fur Pflanzenzuchtung, v.52, p.127-138, 1965.

YAN, W.; KANG, M.S. GGE biplot analysis: a graphical tool for breeders, geneticists, and agronomists. Boca Raton: CRC Press, 2002. 224p. DOI: 10.1201/9781420040371.

YAN, W.; KANG, M.S.; MA, B.; WOODS, S.; CORNELIUS, P.L. GGE biplot vs. AMMI analysis of genotype-by-environment data. Crop Science, v.47, p.643-653, 2007. DOI: 10.2135/ cropsci2006.06.0374.

ZOBEL, R.W.; WRIGHT, M.J.; GAUCH, H.G. Statistical analysis of a yield trial. Agronomy Journal, v.80, p.388-393, 1988. DOI: 10.2134/agronj1988.00021962008000030002x.

Recebido em 12 de janeiro de 2014 e aprovado em 28 de fevereiro de 2014

Pesq. agropec. bras., Brasília, v.49, n.3, p.163-172, mar. 2014

DOI: $10.1590 / \mathrm{S} 0100-204 X 2014000300002$ 